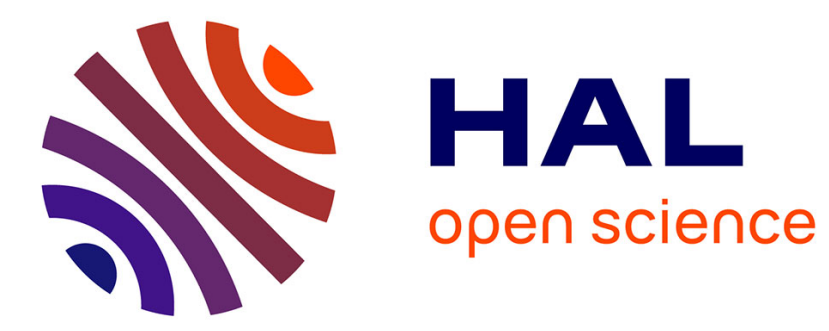

\title{
Cluster dynamics in the collapsing Soviet shipping network
}

\author{
Rawya Zreik, César Ducruet, Charles Bouveyron, Pierre Latouche
}

\section{To cite this version:}

Rawya Zreik, César Ducruet, Charles Bouveyron, Pierre Latouche. Cluster dynamics in the collapsing Soviet shipping network. César Ducruet. Advances in Shipping Data Analysis and Modeling. Tracking and Mapping Maritime Flows in the Age of Big Data, Routledge, pp.317-337, 2017, Routledge Studies in Transport Analysis, 9781138280939. hal-01623593

\section{HAL Id: hal-01623593 \\ https://hal.science/hal-01623593}

Submitted on 12 Nov 2021

HAL is a multi-disciplinary open access archive for the deposit and dissemination of scientific research documents, whether they are published or not. The documents may come from teaching and research institutions in France or abroad, or from public or private research centers.
L'archive ouverte pluridisciplinaire HAL, est destinée au dépôt et à la diffusion de documents scientifiques de niveau recherche, publiés ou non, émanant des établissements d'enseignement et de recherche français ou étrangers, des laboratoires publics ou privés. 


\title{
Cluster dynamics in the collapsing Soviet shipping network
}

\author{
Rawya ZREIK, César DUCRUET, Charles BOUVEYRON, Pierre LATOUCHE
}

Pre-final version of the chapter published in Ducruet C. (Ed.) (2017) Advances in Shipping Data

Analysis and Modeling. Tracking and Mapping Maritime Flows in the Age of Big Data, Routledge

Studies in Transport Analysis, pp. 317-337.

Port and shipping dynamics during the Soviet period is not a very popular topic for scholars. In their review of about 400 scientific articles on ports published in geography journals since 1950, Ng and Ducruet (2014) could only find two papers focusing on socialist ports, one on Odessa published in 1964, and another on Poland in 1986. Ports and shipping do not constitute a common field of interest for specialists on Russia and socialist economies either. Over the past decades, geographers such as Thorez (1998a, 1998b) devoted their attention to socialist shipping trends (Vigarié, 1995) documenting the changes affecting post-Soviet ports following the collapse of the Union of Soviet Socialist Republics (hereafter USSR). While ports in Eastern Europe (Ledger and Roe, 1993), and in the Baltic in particular (Serry, 2011; Thorez, 2011), as well as the special case of North Korea (Ducruet et al., 2009), received a lot of their attention, the bulk of research on ports and shipping concentrated on developed and developing countries in the capitalist world, one exception being China, given its rapid economic growth since the Open Door Policy (see Wang and Ducruet, 2013). Such works primarily insisted on the important changes and uneven adaptation of ports and shipping flows to the various influences of political transitions on trade activities (see Chapter $\mathbf{8}$ for an analysis of the Black Sea liner shipping network). Yet, a global approach to the way USSR ports and maritime networks experienced the collapse remains lacking today.

The aim of this chapter is to fill this gap and to place the topic within the broader, transdisciplinary field of network science. Network analysis has become a strong discipline, which is no longer limited to sociology as it applies to many areas, such as biology, geography or history (Zreik, 2016). The USSR provides great potential for such research since it presents us with the case of a major shock affecting a vast economy, and the objective of testing its collapse on its internal and external maritime linkages. Many aspects that have become paramount in network analysis are, for instance, how spatial networks evolve in relation to distances and proximities of all kinds, and how disruption affects connectivity. Another research pathway is to test such effects on the emergence of communities (or clusters) in a given network. 
The most recent statistical methods for the modeling and processing of relational data are generally based on the stochastic block model (SBM) (Wang and Wong, 1987; Nowicki and Snijders, 2001). The SBM model assumes that each vertex belongs to a latent group, and that the probability of connection between a pair of vertices depends exclusively on that group. Among the recent extensions of the SBM model is the random subgraph model (RSM) proposed by Jernite et al. (2013), which aims at modeling categorical edges using prior knowledge of a partition of the network into subgraphs. The subgraphs are assumed to be made of latent clusters, which have to be inferred from the data in practice. The vertices are then connected with a probability depending only on the subgraphs, whereas the edge type is assumed to be sampled conditionally on the latent groups.

In this work, we consider the methodology introduced in Zreik et al. (2016) that permits the inference of a dynamic version of the RSM model on real data. Our approach allows us to analyze the evolution of USSR-related maritime flows between ports of the world over ten years (1987-1996) through the traffic of ships. Our main hypothesis is that the topology and spatial distribution of flows, the emergence of clusters, and the impact of the collapse are determined by the political belonging of port nodes. This is questionable since shipping networks both reflect and transgress the border effects that characterize the markets that they help to connect.

The next section provides a review of port and shipping dynamics in Russian and Soviet ports based on the few available scholarly works on the subject. It also provides a methodological standpoint with preliminary analyses based on the definition of the USSR maritime ego network to identify main traffic trends. This is followed by the application of stochastic methods to reveal how the topology of this network has evolved according to the political belonging of port nodes before, during, and after the USSR collapse of the early 1990s. The conclusion discusses the contribution of this analysis to broader research on socialist economies, ports and shipping, and spatial network analysis in general.

\section{Socialist ports and maritime transport: from bipolarization to}

\section{globalization}

\section{General trends in USSR shipping}

Traditionally, socialist economies are believed to develop through mainly continental relationships among preferential trade partners (Vigarié, 1995), thereby neglecting maritime transport as a growth engine. Such a conception inherited from the Marxist-Leninist economy theory rapidly lost ground from the 1960s onwards, given the necessity for 
socialist powers to expand their relationships internally and with the rest of the world, whether for commercial or military purposes, through a growing network of friendly partners in the extended socialist and developing world (e.g. Cuba, Vietnam and Africa). Thus, the Soviet Union gradually strengthened its global influence by competing with the capitalist world along all major maritime routes, as reflected in the continuous growth of its total port tonnage (Vigarié, 1995) in the 1970s-1980s, despite cumbersome customs regulations and deficient port infrastructures. Yet, in the early 1980s a total 240 million tons of maritime trade remained coastal (16.5\%), with socialist partners $(32.1 \%)$, developing countries (6.1\%), and capitalist countries (45.3\%) (Thorez, 1998a).

The ambition of this chapter is to shed new light on the impact of a major geopolitical shock on the topology and spatial distribution of a spatial, -in our case, maritime- network. This shock is multifaceted. Its chronology is well known, with the dismantlement of the COMECON (Council for Mutual Economic Assistance) in June 1991, impacting strongly on Soviet foreign trade; the dissolution of the Warsaw Pact in July 1991; and the partition of the USSR itself in December 1991, immediately followed by the constitution of the Commonwealth of Independent States (CIS). Such events are both a cause and a consequence of the weakening Russian economy throughout the 1980s, leading to a sudden drop in trade exchanges, a disorganization of former relationships, and a growing debt, all resulting in a reorganization of ports and maritime networks (Vigarié, 1995).

The aforementioned reorganization is well documented by the works of Thorez (1998a, 1998b) and can be synthesized as follows: prior to the disintegration of the USSR, ports and maritime transport were characterized by a spatial and functional division of labor centered upon and organized from Moscow. Soviet shipping companies were specialized in certain trades and routes, each having their base or hub port at locations around the block from the Baltic Sea to the Far East. Certain large ports were multifunctional, while others remained specialized in specific commodities, mainly raw materials and intermediate inputs, given the late adoption of containerization in the USSR. The 1991 collapse had been a "brutal thunderstruck" (Thorez, 1998a, p. 13) forcing port authorities and shipping companies to rethink their activity in terms of hinterland supply chains and management in a context of falling demand and traffic decline. Such a decline -the whole USSR area concentrated no more than $3.5 \%$ of world maritime trade in 1994- was accentuated by the modal shift of traffic from sea to land (road, rail), especially towards West European transit hub ports, such as Antwerp, Rotterdam, and Hamburg, thereby causing a severe decline at a number of postSoviet ports. The shrinking of maritime trade had been severe internally (coastal shipping) while former Soviet ports, including those in Russia, strove to diversify their traffic to compensate the loss of their formerly vast hinterland. 
The shock was felt differently among countries and ports depending on their capacity to adapt to a new competitive and global environment and the importance given to maritime trade for domestic demand or transshipment; although in relative terms, maritime traffic volumes declined less (-42\%) than total transport traffic (-49.6\%) between 1990 and 1995 (Thorez, 1998b). This is because certain ports recovered more quickly from the shock than others: positively in the Baltic and Far East regions, negatively in the Black Sea and in Russia itself. The process was characterized by many of the republics of the Soviet Union declaring their independence and being recognized as sovereign nation-states.

\section{Constructing the Soviet ego network: preliminary results}

Despite our current knowledge of the impact of the disintegration of the USSR on ports and maritime transport, to date the relational or network perspective had not been contemplated. Such a major event in economic and political terms provides fertile ground for the study of the changing topology and geography of a spatial network. For that purpose, we constructed the (maritime) ego network of the USSR defined by internal (intra-USSR vessel movements) and external (vessel movements between USSR ports and other ports, and between the latter ports) relationships, based on the Lloyd's List database over the period 1987-1996. This corresponds to the definition of the ego network in social network analysis (Wasserman and Faust, 1994). Such a network places the USSR at the core of the analysis, leaving aside the rest of the global maritime network, (i.e., vessel movements between ports not at all connected with the USSR). The choice of the period (10 consecutive years) is justified by the need to verify the true impact of the shock that lies in the middle of the period (1991). Yet, it is acknowledged that the economic downturn of Russia and the USSR already started long before the collapse itself, namely, already in the late 1980s. Overall, this methodology allows us to get closer to the shock and reduce the noise caused by unrelated factors. For each year under study, we compiled four complete months of vessel movements between such ports, taking into account not only adjacently connected ports but also intermediary stops along the whole voyage during the months of March, June, September, and December, to avoid the effect of trade seasonality. As a result, the spatial pattern of aggregated USSR shipping traffic during the study period reveals its concentration in the vicinity, along Russian, Soviet shores, especially in the Baltic and Black Seas for the largest (volume) and most specialized (share) nodes (Figure 19.1). Elsewhere, high shares of USSR traffic in total port traffic are clearly visible in partner, or politically close, countries, despite the distance: Cuba, Algeria and Vietnam, but also in small groups of ports in Peru, India, and Canada. Due to physical proximity and regardless of political affinities, certain nodes emerge on the world map, such as several specialized ports in Japan (Far East Russian trade), Helsinki and Hamburg, as the most specialized of the largest, non-Soviet nodes, as 
well as Rotterdam and Antwerp, which both act as multifunctional/transshipment ports as mentioned above.

[Figure 19.1]

We also measure traffic evolution per political group or subgraph: USSR, Eastern Block, other socialist ports, as well as non-aligned and capitalist ports (Figure 19.2). The "other socialist" group is composed of ports in countries having had socialist elements in their political constitution at a given point in time of their contemporary history. Our results confirm the aforementioned trends in several ways, namely: (1) total traffic of USSR ports; (2) traffic of each subgraph relative to the year 1991; (3) traffic between USSR and each subgraph relative to the year 1991; and (4) internal traffic of each subgraph. As expected and coinciding with the collapse, USSR ports witnessed a sharp slowdown in the years 19911992 after a period of growth, followed by rapid recovery, as seen over the broader 19772008 period based on the same database. Each subgraph went through distinct evolutions, however. Relative to the year 1991, USSR ports are the ones handling the highest traffic prior to the collapse, while Eastern Block ports already faced decline in 1989-1990, but recovered more rapidly than the USSR. Ports of the "other socialist" subgraph went through a slowdown comparable to the USSR after 1991 and before recovery. Interestingly, ports in non-aligned and capitalist countries did not much suffer from the demise of the USSR, given the stability of their growth over the period. Traffic evolution between the USSR and other subgraphs reveals complementary trends. For instance, based on the year 1991, USSR traffic preferentially connected "brother" countries prior to its collapse, while such traffic became relatively more important with the Eastern Block afterwards and also internally (intra-USSR). Thus, the dissolution of the USSR affected long-distance relationships, such as those with "other socialist" countries to a greater extent and less so within its vicinity. The share of intra-group traffic shows that in this ego network flows among capitalist ports dominate around $80 \%$ on average despite a slight decline; non-aligned ports increased a noticeable share of mutual linkages, from about $35 \%$ to nearly $50 \%$; while all socialist ports in the three other subgraphs exhibit a very low internal share, given their reliance on external, nonsocialist ports to connect with the rest of the world but also with each other. In fact, USSR traffic mainly connected capitalist ports ( $70 \%$ on average), followed by intra-Soviet traffic $(10 \%)$, other socialist (8\%), Eastern Block (6\%) and non-aligned ports (6\%), with little change over time.

[Figure 19.2] 


\section{The model of dynamic random subgraphs}

The remainder of the analysis involves the application of the dynamic random subgraphs model (dRSM) (Zreik et al., 2016) on a slightly different network whereby USSR ports and Eastern Block ports are grouped into the same subgraph, given their geographic and political proximity and their relatively low number (Figure 19.3). In addition, network analysis only applies to ports connected every single year during the period, thereby leaving aside a number of fluctuating ports. Despite much discrepancy due to the overwhelming importance of capitalist ports, our port sample is as follows: 48 USSR ports, 17 Eastern Block ports (65 in total for both), 77 other socialist ports, 93 non-aligned ports, and 584 capitalist ports. This sample consists of 819 ports within the 2,691 ports connecting the USSR during the period, which means about $30.4 \%$ of all ports, but mainly large traffic nodes.

[Figure 19.3]

In the following section, we describe the dynamic RSM (dRSM) model, as introduced in Zreik et al. (2016). Thus, we consider a set of $T$ networks $\{G(t)\} T t=1$, where $G(t)$ is a directed graph observed at time $t$ and for which a partition $P(t)$ of $S$ subgraphs is also known. Each $G(t)$ is represented by its $\mathrm{N}_{-} \mathrm{N}$ adjacency matrix $\mathrm{X}(\mathrm{t})$ and $\mathrm{N}$ denoting is the number of nodes (assumed constant over time). No loops are considered. The edge $\mathrm{X}(\mathrm{t}) \mathrm{ij}$, describing the relationship between nodes $i$ and $j$ is assumed to take its values in $\{0, \ldots \mathrm{C}\}$ such that $X(t) i j=$ $\mathrm{c}$ means that nodes $\mathrm{i}$ and $\mathrm{j}$ are linked by a relationship type $\mathrm{c}$ at time $\mathrm{t}$ and $\mathrm{X}(\mathrm{t}) \mathrm{ij}=0$ indicates the absence of relationship. Our goal is to cluster at each time $t$ the $\mathrm{N}$ nodes into $\mathrm{K}$ latent groups with homogeneous connection profiles, (i.e. find an estimate at each time $t$ of the binary matrix $Z$, which is such that $Z(t) i k=1$ if at time $t$, the node $i$ belongs to the class $k$, and 0 otherwise). In our maritime application the $Z(t)$ ik $=1$ if at time $t$, the port $\mathrm{i}$ belongs to the class $k$, and 0 otherwise; however the type of connections between ports is binary in this application, so $X(t) i j=1$ means that port $i$ and $j$ are linked by a one or several ships at time $t$ and $X(t) i j=0$ indicates the absence of relationship.

\section{The dRSM model at each time $t$}

The network is assumed to be generated at each time $t$ as follows: each vertex $i$ is first associated to a latent class $\mathrm{k}$ with a probability depending on the subgraph to which it belongs. So, we assume that for a number $K$ of latent groups given, the variable $Z(t) i$ is drawn from a multinomial distribution of parameter_(t) si : 


$$
Z_{i}^{(t)} \sim \mathcal{M}\left(1, \alpha_{s_{i}}^{(t)}\right)
$$

where_(t) $s=\left(\_(t) s 1 ;::: ; \_(t) s K\right)$ is the vector of prior probabilities of the $K$ latent groups in the subgraph $\mathrm{s}$ at time $\mathrm{t}$ and is such that PKk=1_(t) $\mathrm{sk}=1 ; 8 \mathrm{~s} 21 ;:::$; $\mathrm{s}$ : On the other hand, we assume that the type of link between nodes $i$ and $j$ is sampled from a multinomial distribution depending on the latent vectors $Z(t) i$ and $Z(t) j$,

$$
X_{i, j}^{(t)} \mid Z_{i k}^{(t)} Z_{j l}^{(t)}=1 \sim \mathcal{M}\left(1, \Pi_{k l}\right),
$$

with_kl $2[0 ; 1] \mathrm{C}+1$ and $\mathrm{PC} \mathrm{c}=0 \_\mathrm{klc}=1$.

Modeling the evolution of random subgraphs

We present a hidden state, in the form of a state-space model to model the evolution of the subgraphs over time (Figure 19.4). So, we introduce a new latent variable (t) $\mathrm{s}$, which is assumed to be distributed according to a normal distribution with mean $B_{-}(t)$ and covariance matrix _ :

$$
\gamma_{s}^{(t)} \sim \mathcal{N}\left(B \nu^{(t)}, \Sigma\right)
$$

[Figure 19.4]

Note that this variable which was introduced in our model for characterizing temporal processes, could make the link between the proportions of subgraphs _ $(t) s$ at different times through a logistic transformation, in the form:

$$
\alpha_{s k}^{(t)}=\exp \left(\gamma_{s k}^{(t)}-C\left(\gamma_{s}^{(t)}\right)\right), \quad \forall k=1, \ldots, K-1,
$$

where $C((t) s)=P K$ 回 ${ }^{`}=1 \exp \left((t) s^{\prime}\right)$ and _(t $s K=1$ 回 PK?1 ${ }^{`}=1 \exp \left(\_(t) s^{\prime}\right)$. 
The variable _ $(t) s$ is generated by sampling $(k$ a 1$)$ of the components of $(t) s$ according to normal distribution with mean $\mathrm{B}_{-}(\mathrm{t})$ of dimension ( $\mathrm{K}$ ? 1 ) and a covariance matrix _ of size (K [ 1) _ ( $K$ ? 1). The last component of the vector $(t) s$ is arbitrarily set to zero. Due to that $(t) s$ has a ( $K$ : 1) degree of freedom. The rest of the modeling includes a classic state-space model for linear dynamic systems that evolves over time. The model is as follows:

$$
\left\{\begin{aligned}
\nu^{(t)} & =A \nu^{(t-1)}+\omega \\
\gamma_{s}^{(t)} & =B \nu^{(t)}+v \\
\nu^{(1)} & =\mu_{0}+u
\end{aligned}\right.
$$

where $A$ and $B$ are two transition matrices of size ( $K$ ? 1 1)_( $K$ ? 1 ). The terms of noise !, $u$ and $v$ are supposed to be Gaussian such as!_ $\mathrm{N}\left(0 ;{ }_{2}\right) ; \mathrm{v}_{-} \mathrm{N}\left(0 ;{ }_{-}\right) ; \mathrm{u}_{-} \mathrm{N}(0 ; \mathrm{V} 0)$ : Finally, our model has three latent variables $\left(\_; \mathrm{Z}\right)$, and is parameterized by $\_=\left(\_0 ; \mathrm{A} ; \mathrm{B} ; \_; \mathrm{V} 0 ; \_; \_\right)$. This model is called the dynamic random subgraph model (dRSM). Figure 2 presents the graphical model for dRSM.

The inference of the model relies on variational EM bounds as an algorithm. The number of clusters is estimated using a BIC criteria. For more details, we refer to Zreik et al. (2016).

\section{Main results}

In this section, we apply the methodology associated with the dRSM model to the maritime flows data, which describes the varied traffic between 819 ports active in the world at each time t. Here, we concentrate on the period around the occurrence of this event in 1991, studying it over 10 consecutive years (1987-1996). As this event impacted Socialist countries more than others, we decided to analyze the aforementioned four subgraphs based on their political category. Therefore, the network is a directed network without loops and binary : C $=1$ and $\mathrm{Xt} i \mathrm{j}=1$ if $\mathrm{i}$ and $\mathrm{j}$ exchanged at least one ship during the period $\mathrm{t}, 0$ otherwise, with $\mathrm{t}$ $2 \mathrm{f} 1 ;::$ : ; $10 \mathrm{~g}$ and $S=4$, we looked for $K=6$ clusters in the data.

By construction, the matrix _ veri_es _kl0 + _kl1 $=1 ; 8(\mathrm{k} ; \mathrm{l})$ therefore, only _kl1 term, describing the connection probabilities given in Table 19.1 .

[Table 19.1] 


\section{Topological and functional trends}

One first result is the identification of clusters composing the USSR ego network, based on their connection probabilities and intra vs. inter-class probabilities (Figures 19.5 and 19.6). This allows us to define clusters 1 and 3 as the "cores" of the network, as they connect all other clusters, connect each other, and have a noticeable amount of internal connectivity. All other clusters connect these cores, but differ in terms of size (i.e. number of ports), while clusters 4 and 6 are the only ones among them to share a mutual connection. Clusters 2 and 5 have no mutual relationships, and cluster 2 has no internal connectivity. We can thus infer a strong opposition between the core and several peripheries that do not otherwise connect. The rest of the analysis will investigate whether such a core-periphery pattern reflects the bipolarization of the world; if it reflects other logics; what is the role of USSR ports in such a pattern; and how did the political transition affect the geographic distribution of clusters over time.

[Figure 19.5]

[Figure 19.6]

Our main results point to a body of evidence relating to the specific evolution of each cluster depending on each subgraph (Figure 7). Overall, the USSR collapse is largely responsible for the sudden growth or decline of group proportions, especially for the years 1991-1993. Core clusters 1 and 3 that dominate the entire network exhibit very different evolutions during this transition. Cluster 3, the most central cluster, lost significance for USSR and Eastern Block ports in 1991-1993, until a recovery in 1995-1996. By comparison, the same cluster gained ground for non-aligned ports and other socialist ports, and underwent a slight decline for capitalist ports. Thus, the demise of the USSR had been most detrimental with a direct effect on communist ports and perhaps on capitalist ports well-connected to the USSR and Eastern Block. The other core cluster 1 reveals another similarity between USSR/Eastern Block and capitalist ports during the collapse, with a growth as opposed to a decline for other socialist and non-aligned ports. In fact, the tight interdependence between communist and capitalist markets, despite their political opposition, led to similar effects during the shock in both blocks.

[Figure 19.7]

When it comes to peripheral clusters, some of them display drastically different behavior from one subgraph to the other. The largest of these in terms of number of ports, cluster 4 , registered a considerable decline in importance in all subgraphs except for the capitalist one. The opposite trend occurred for cluster 5 , bearing in mind that these two clusters only connect indirectly, through a different core cluster. The most peripheral cluster 2 increased 
its proportion in all subgraphs, while the smallest cluster, number 6, did not witness any particular trend over time. These evolutions shed new light on the topological and functional trends characterizing world ports and their connectivity during the disintegration of the USSR. In other words, the two cores of the network (clusters 1 and 3) have an opposite behavior during the collapse, with communist and capitalist ports losing importance in the main core (cluster 1 ) and gaining importance in the secondary core (cluster 3 ). The two large semi-peripheries (clusters 4 and 5 ) also show an opposition, but this time between capitalist ports and all other ports. Capitalist ports gain importance in the largest and best-connected cluster 4, while other socialist, non-aligned, and USSR-Eastern Block ports gain importance in cluster 5 , which strongly connects the main core cluster 1 . The most peripheral cluster 2 increased its importance mainly for other socialist and USSR-Eastern Block ports, suggesting that becoming peripheral had been mainly the case of socialist/communist ports.

\section{Spatial trends}

Based on the aforementioned topological and functional trends that characterize the evolution of the USSR ego network and its components, it is crucial to investigate the changing spatial embeddedness of identified clusters on the world map (Figure 19.8). The core cluster 1 is principally composed of European ports, including most of the largest gateways and hubs along the so-called North European Range (e.g. Le Havre, Antwerp, Rotterdam, and Hamburg) but also Felixstowe, Dunkirk, Liverpool, London, Bremerhaven, and a number of meridional ports like Algeciras, Bilbao, and Piraeus. These gateways and hubs are crucial for the USSR to connect to the rest of world although they belong to capitalist economies, because they act as modern transshipment nodes in the global shipping network not only for the USSR but also for an extended Europe as a whole. It is worth noting that many USSR and Eastern Block ports belong to the same cluster, featuring ports from Russia, Poland, East Germany, and Baltic States and more on the Scandinavian shores of the communist maritime system.

With the demise of the USSR, several of the aforementioned ports remained in cluster 1 , regardless of whether capitalist (e.g. Le Havre-Hamburg range) or communist (e.g. St. Petersburg); but the cluster took on a different geographic scope, with the addition of many more non-European ports (New York, Los Angeles, Hong Kong, Singapore, Japan, Brazil, Mediterranean ports) and a number of large communist ports (e.g. Odessa, Constantza). All other ports shifted to cluster 3 , as mentioned above, composed mainly of small and medium-sized North European ports. One of the main effects of the USSR collapse on core clusters is thus the shift of a few large communist ports in the center of the system (cluster 1) together with the world's largest ports. The dislocation of the USSR thus provoked a 
displacement of the network's center of gravity towards the largest external hubs mainly, because of the loosening political significance of flows. All other communist ports shifted to other, more peripheral, clusters. Before looking at these clusters, it is interesting to note that cluster 6 , which does not react to the collapse in any subgraph, is geographical by nature, (i.e. mainly composed of Asian and Oceanian ports). Certain Chinese and Vietnamese ports, which belonged to the "other socialist" subgraph and to the peripheral cluster 2 in the late 1980s, became fully part of cluster 6 after the collapse. Geographic proximity and regional integration effects thus gradually superseded former political factors influencing the fading pattern of Soviet trade between former brother countries.

The evolution of cluster 2, the most peripheral and extroverted cluster, is interesting as it shows a group of mainly small and medium-sized ports, with a sizeable proportion of communist ports (USSR and other socialist regions such as China, Vietnam, and North Korea), absorbing many more ports on all continents during the collapse, but without losing its original composition. This means that the collapse created more peripheral ports due to trade reorientation, but these ports maintained their linkages with the core of the system (cluster 1). Geographically, cluster 2 expanded mainly towards the Americas and the Mediterranean/Black Sea, but also to South Asia (e.g. India). The case of Cuba's main port, Havana, is emblematic of such a trend, which suggests a shrinkage of port and maritime activity during the collapse. This also explains why clusters 1 and 2 share a common feature: the growth of their respective proportions mainly in the "other socialist" subgraph, (i.e. in partner countries of the USSR).

Lastly, in relation to the evolution of semi-peripheries, clusters 4 and 5 also exhibit interesting geographic patterns and shifts. The populous and well-connected cluster 4 , before and after the USSR collapse, is mainly composed of a spatially continuous region including medium- sized Latin American, African, and Mediterranean/West Asian ports. Cluster 5 comprises mostly minor North European and Scandinavian ports. The break-up of the USSR provoked an inversion of these clusters in the years 1991-1993, as they replaced each other on the map. This reinforces the idea of shrinkage and dilatation of Soviet influence during the shock. The likely reason is that cluster 5 is the best connected to the core (cluster 1), so that the shock provoked a connectivity shift from the Old World (North Europe) to the New World (Latin America/Africa/West Asia). The smaller North European ports, well connected to their large European neighbors before the shock at least partly through USSR shipping, became suddenly better connected with the "secondary core" (cluster 3), it too becoming more "European" and more "socialist" (cf. Figure 19.7). Overall, the USSR collapse created a lock-in of small and medium-sized capitalist European ports together with their socialist counterparts, based on geographic proximity and high-density 
linkages, while the rest of the world, outside Europe, became the new core of the system, notwithstanding the permanent presence of a few large socialist ports.

[Figure 19.8]

\section{Conclusion}

The analysis of the Soviet ego network evolution using a recent statistical model called dRSM to analyze a dynamic network with stochastic methods shows a new step towards a better understanding of the influence of political and spatial factors shaping transport and communication systems. Our main results convey the idea that the diminishing importance of political factors in times of crisis gives more importance to geographic proximity and node hierarchy, when a given transport system reorients its trade activities and becomes more embedded in the global maritime network. The crucial importance of geographic proximity had already been underlined in previous studies using various clustering methods on shipping network data (see Bouveyron et al., 2015), but this is the first time that political factors are introduced as a complementary -and perhaps more fertile- dimension.

Yet, if the structure of the USSR ego network and the effect of its dissolution could be well described through such methods as a vital and advanced complement to more classic descriptive statistics, one question remains: why did the network go back to its initial pattern? The short-lasting impact of three consecutive years (1991-1993) is rather surprising, given the end of world bipolarization from those dates. Perhaps, running the same analysis over a longer period would better highlight more profound and structural changes affecting shipping flows. As mentioned earlier, in the late 1980s the USSR had already become a relatively open and highly maritime-oriented economy, compared with the early phases of its development, before and up to the 1960s-1970s. This explains why the observed changes are mainly conjectural, but they were profound. We could also learn from such a shock the relative influence of geography and politics on network structures and dynamics. Further research will refine the analysis by integrating links weights and perhaps focus on the diversity of cargo flows from bulks to containers, while enlarging the time span to better reveal such influences. 


\section{Acknowledgements}

The research leading to these results has received funding from the European Research Council under the European Union's Seventh Framework Programme (FP/2007-2013) / ERC Grant Agreement n. [313847] "World Seastems".

\section{References}

Bishop C.M. (2006) Pattern Recognition and Machine Learning. Springer-Verlag.

Bouveyron C., Latouche P., Zreik R., Ducruet C. (2015) Cluster identification in maritime flows with stochastic methods. In: Ducruet C. (Ed.), Maritime Networks: Spatial Structures and Time Dynamics, London and New York: Routledge Studies in Transport Analysis, pp. 210-228.

Daudin J.J., Picard F., Robin S. (2008) A mixture model for random graphs. Statistics and Computing, 18(2):173-183.

Ducruet C., Roussin S., Jo J.C. (2009) Going West? Spatial polarization of the North Korean port system. Journal of Transport Geography, 17(5): 357-368.

Jernite Y., Latouche P., Bouveyron C., Rivera P., Jegou L., Lamassé S. (2014) The random subgraph model for the analysis of an ecclesiastical network in Merovingian Gaul. Annals of Applied Statistics, 8(1): 377-405.

Ledger G.D., Roe M.S. (1993) East European shipping and economic change: a conceptual model. Maritime Policy and Management, 20(3): 229-241.

Ng A.K.Y., Ducruet C. (2014) The changing tides of port geography (1950-2012). Progress in Human Geography, 38(6): 785-823.

Serry A. (2011) Dynamiques du transport maritime en Baltique orientale. Territoire en Mouvement, 10: 36-48.

Thorez P. (1998a) La difficile mutation des transports maritimes dans la C.E.I. Bulletin de l'Association des Géographes Français, 75(1): 10-29.

Thorez P. (1998b) Le transport maritime dans les pays issus de l'ex-URSS. Le Courrier des Pays de L'Est, 426: 18-52.

Thorez P. (2011) Les enjeux portuaires de la Russie en mer Baltique. Territoire en Mouvement, 10: 49-59. 
Vigarié A. (1995) La Mer et la Géostratégie des Nations. Paris: Economica.

Wang C., Ducruet C. (2013) Regional resilience and spatial cycles: Long-term evolution of the Chinese port system (221BC-2010AD). Tijdschrift voor Economische en Sociale Geografie, 104(5): 521-538.

Wang Y.J., Wong G.Y. (1987) Stochastic blockmodels for directed graphs. Journal of the American Statistical Association, 82: 8-19,

Wasserman S., Faust K. (1994) Social Network Analysis: Methods and Applications. Cambridge UK: Cambridge University Press.

Zreik R. (2016) Statistical Analysis of Networks and Applications in Social Sciences. Doctoral dissertation, Université Paris 1 Panthéon Sorbonne.

Zreik R., Latouche P., Bouveyron C. (2016) The dynamic random subgraph model for the clustering of evolving networks. Computational Statistics, 1-33. 


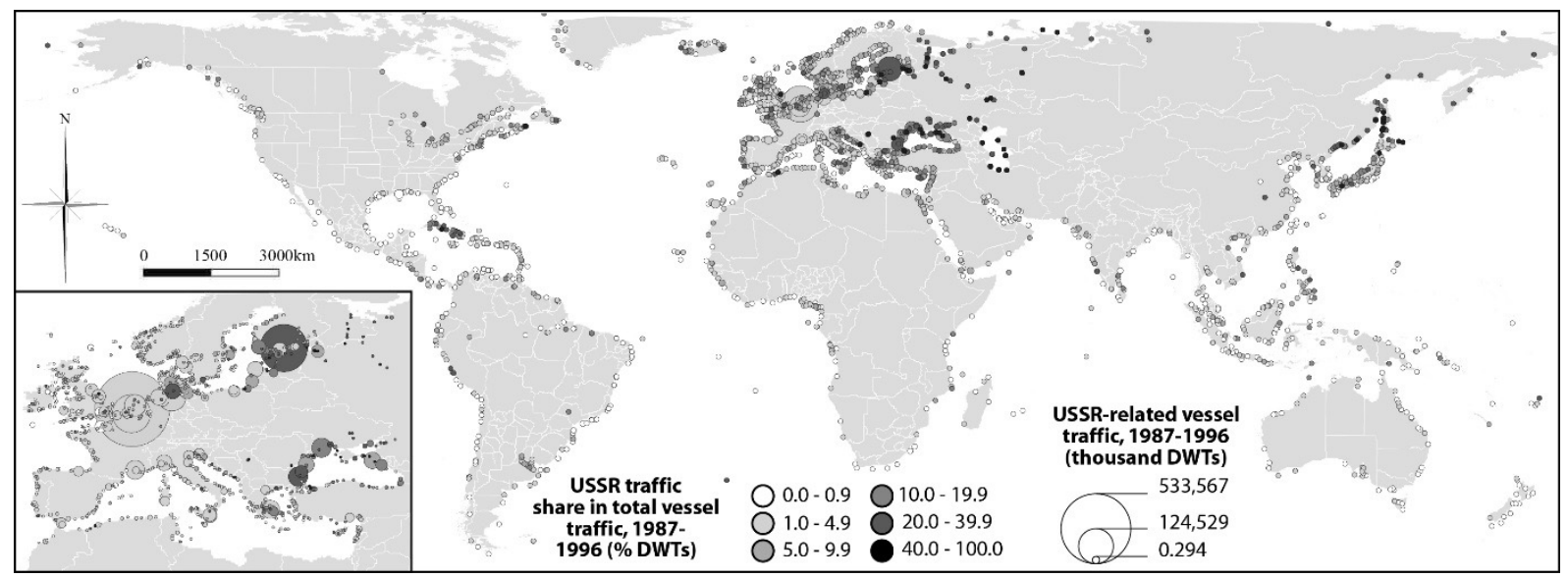

Figure 19.1:. USSR-related traffic volume and share at world ports, 1987-1996

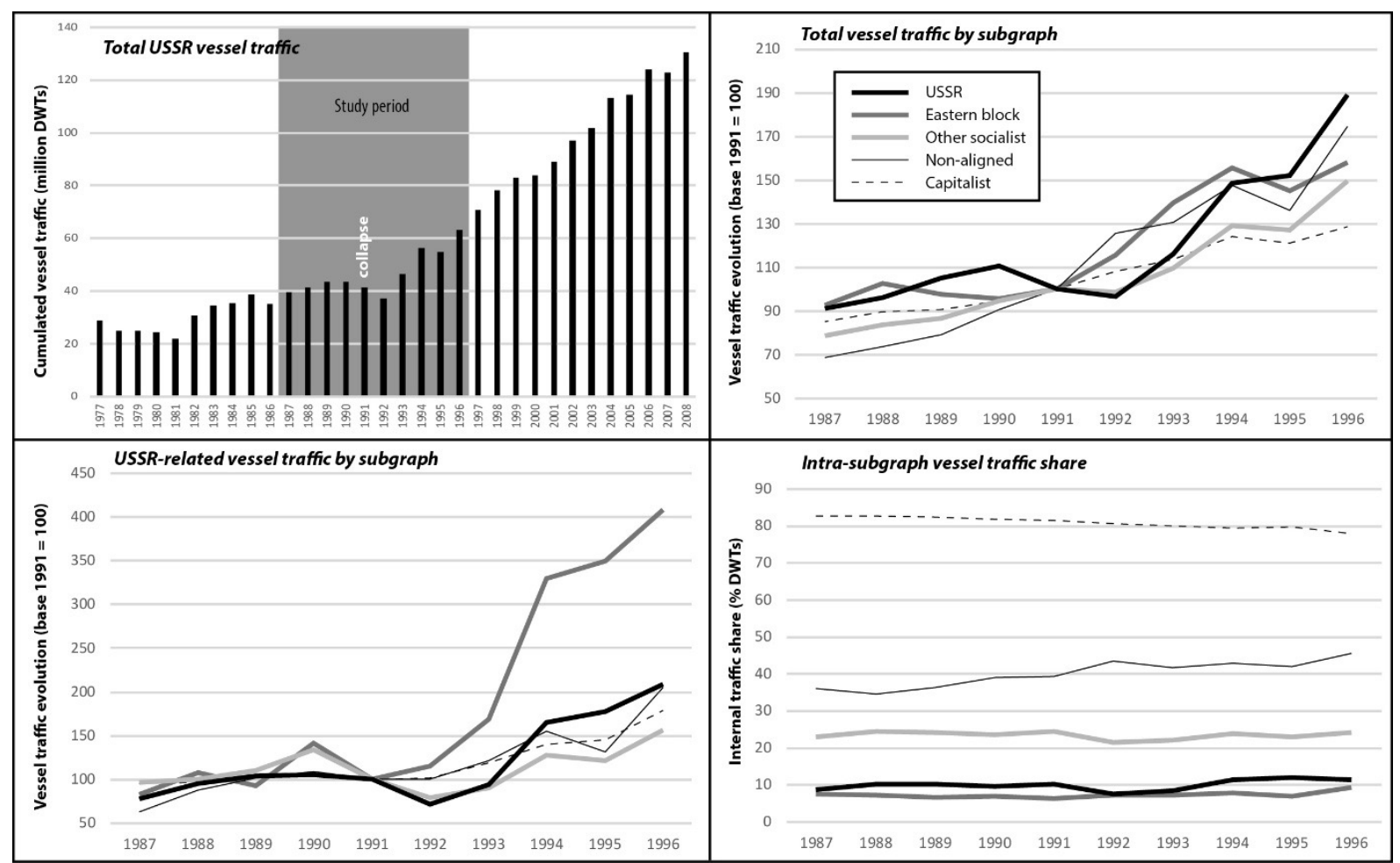

Figure 19.2: USSR-related traffic evolution, 1987-1996 


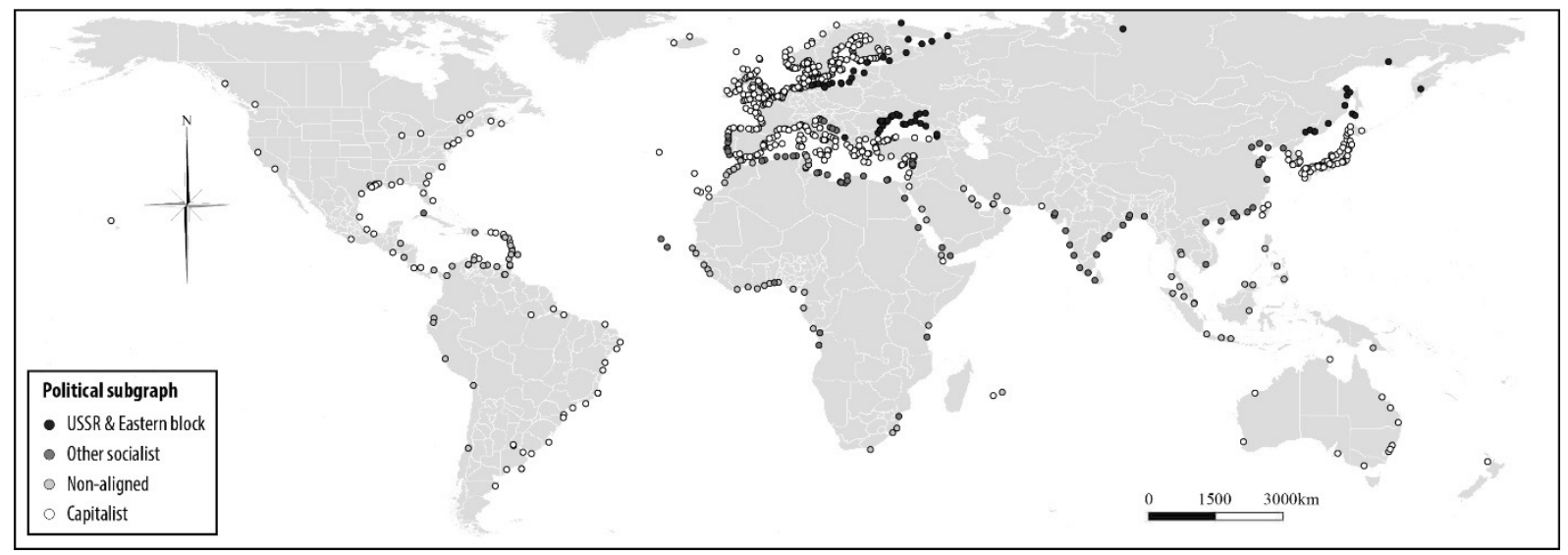

Figure 19.3. World distribution of political ensembles (subgraphs) of ports

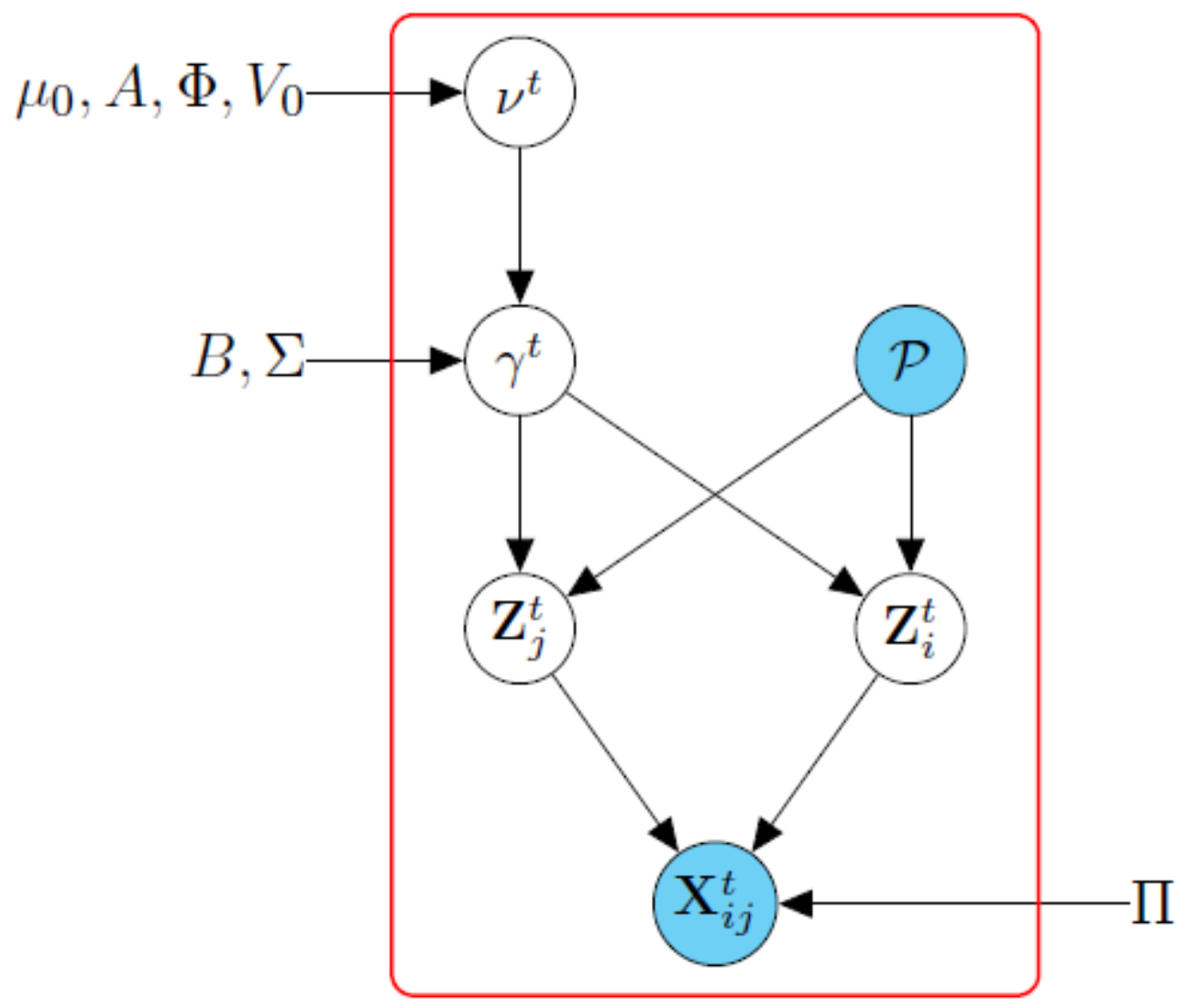

Figure 19.4: The graphical model for dRSM 


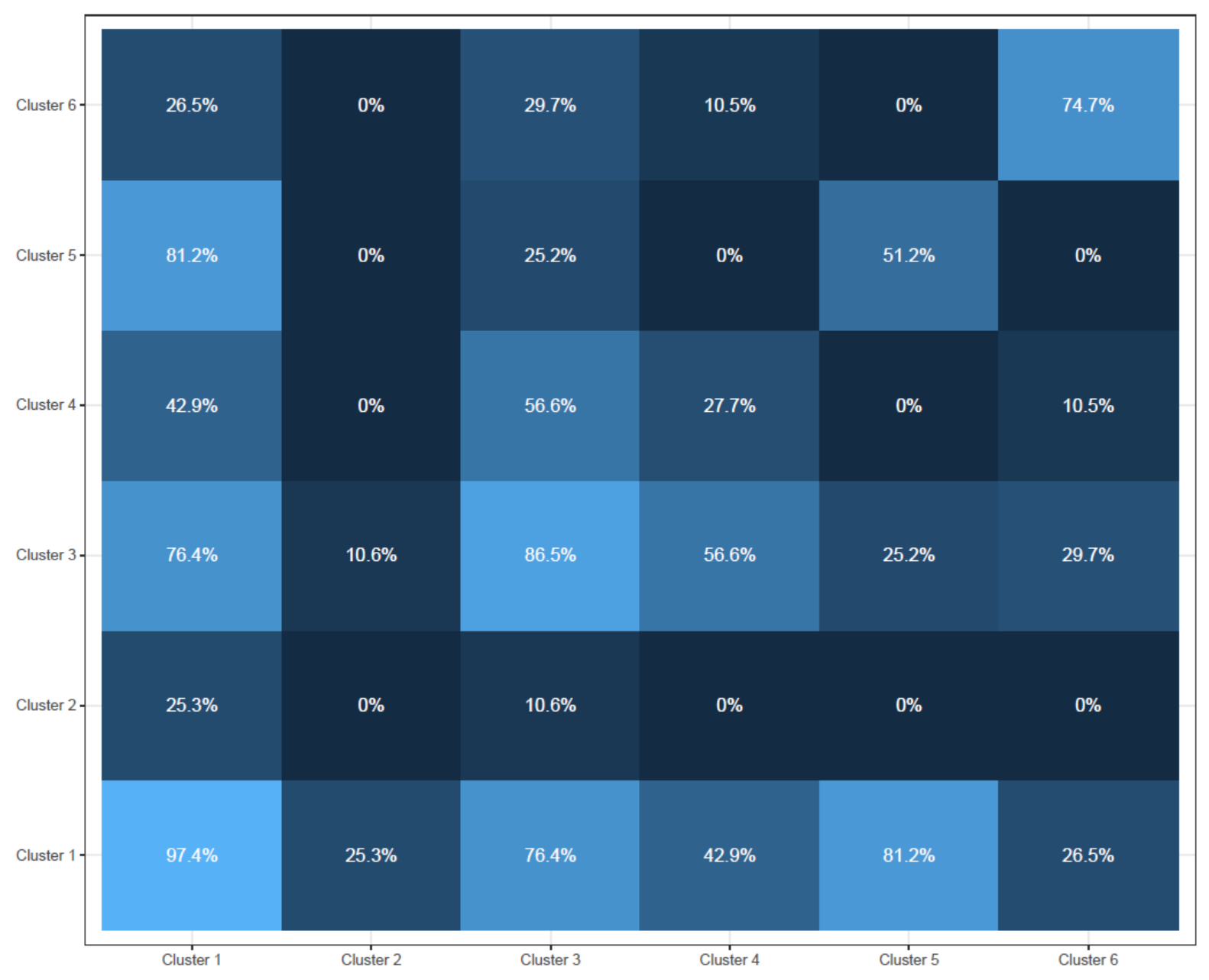

Figure 19.5: Connection probabilities between clusters 


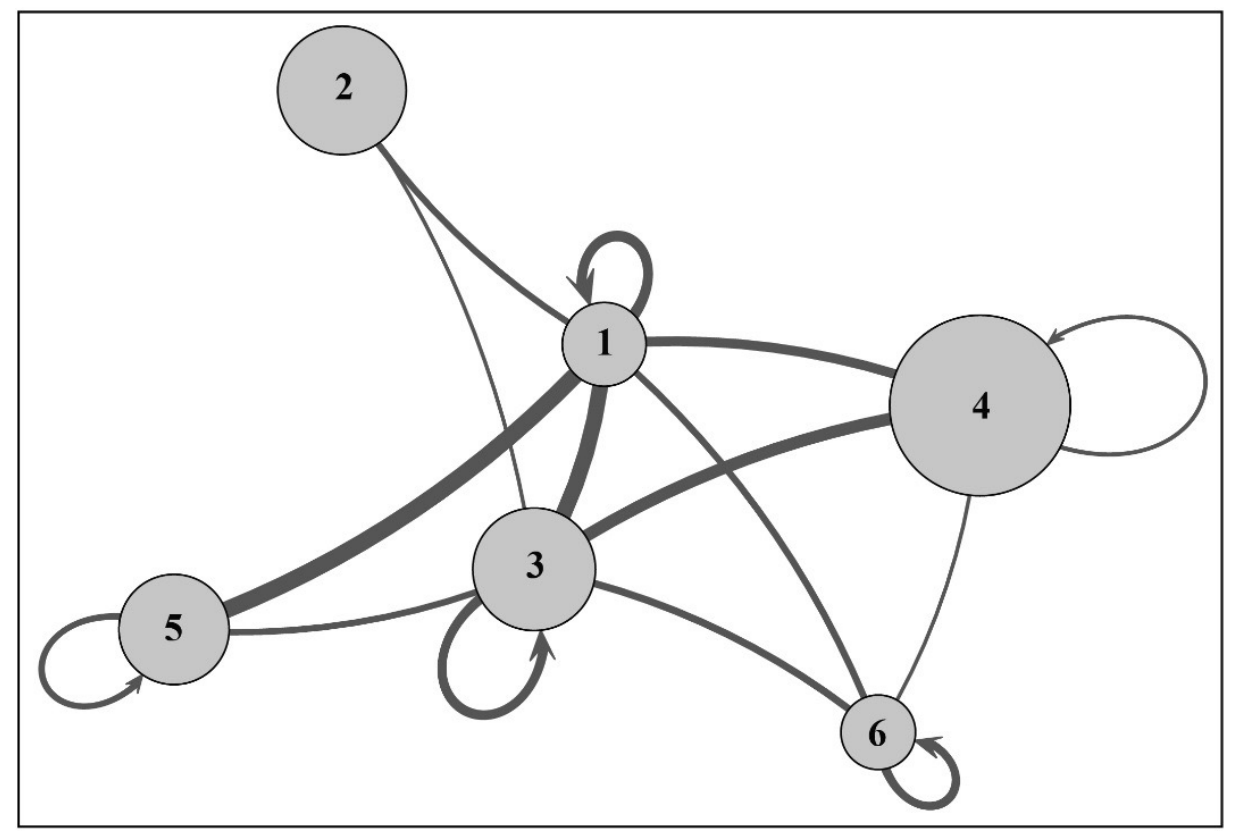

Figure 19.6: Inter vs. intra-class probabilities among clusters

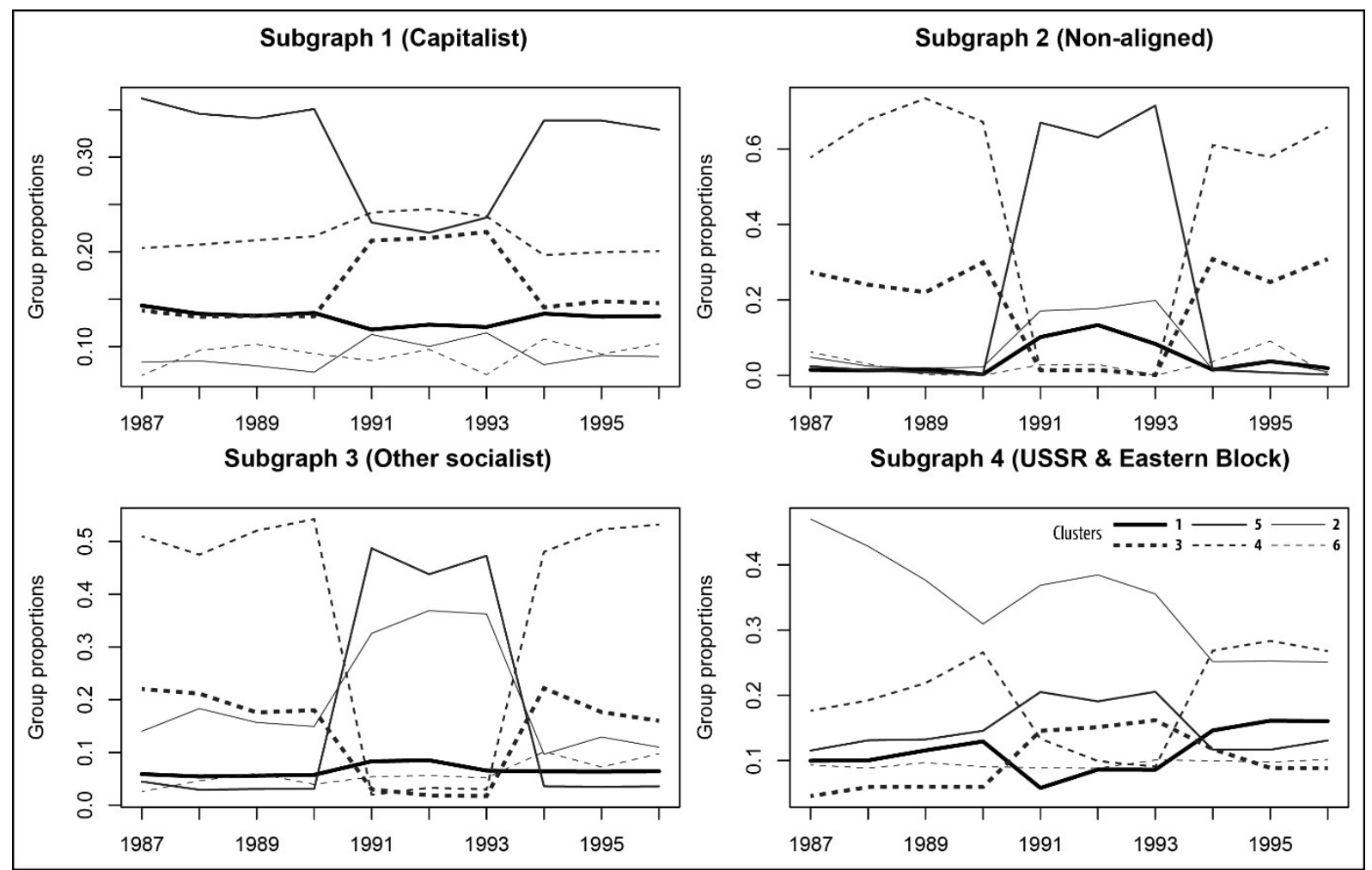

Figure 19.7: Cluster evolution by political subgraph, 1987-1996 
1989

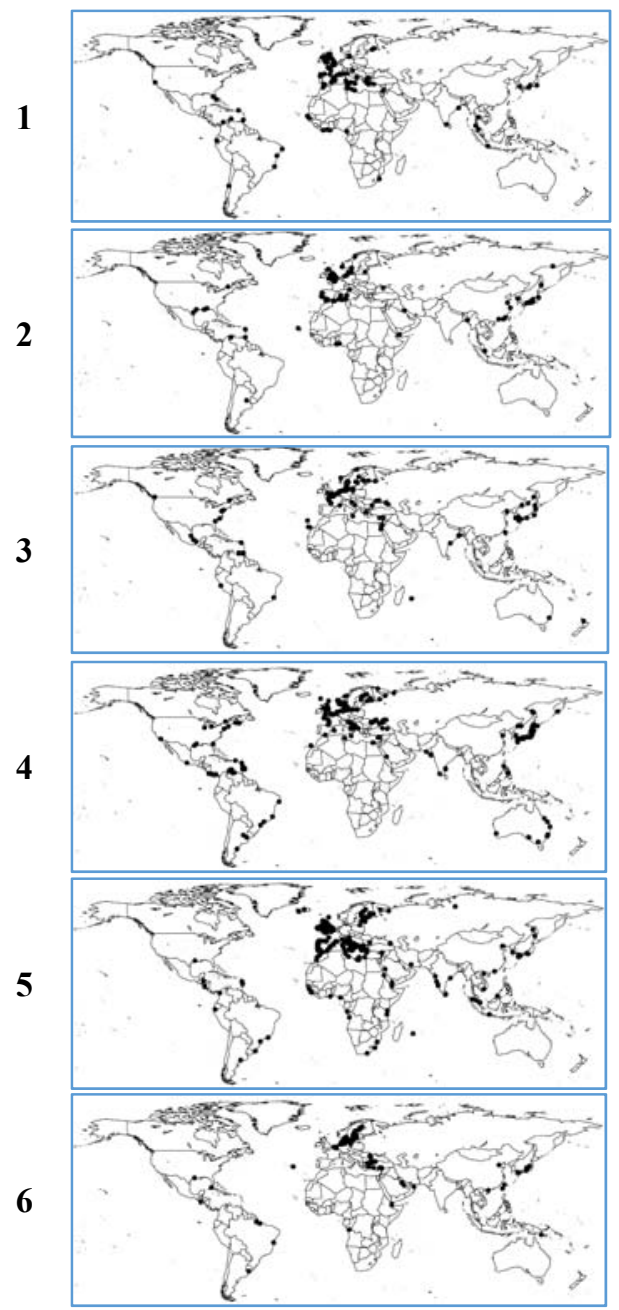

1992

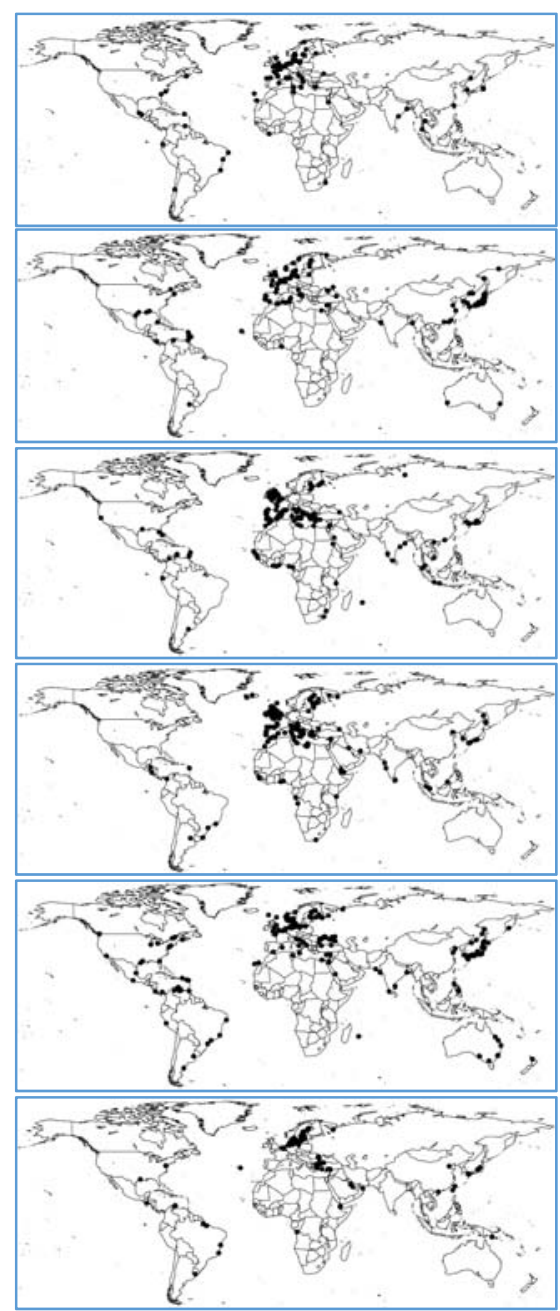

1995

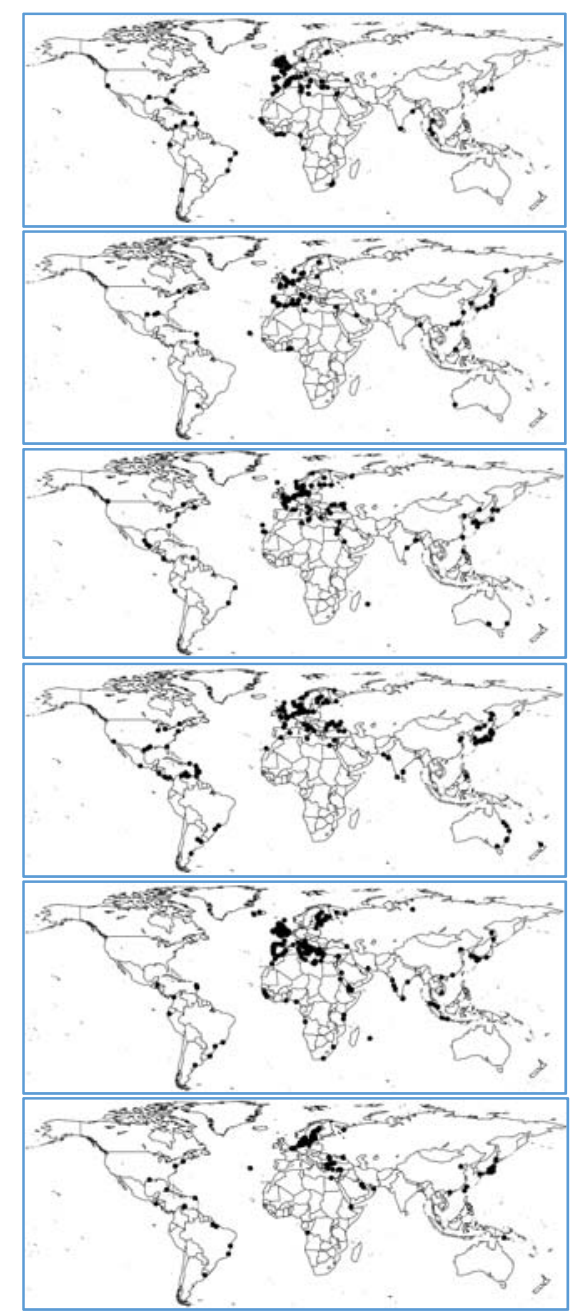

Figure 19.8: Spatial distribution of clusters at selected years

\begin{tabular}{rrrrrrr}
\hline & cluster 1 & cluster 2 & cluster 3 & cluster 4 & cluster 5 & cluster 6 \\
\hline cluster 1 & 0.663 & 0.708 & 0.123 & 0.141 & 0.115 & 0.000 \\
cluster 2 & 0.708 & 0.955 & 0.362 & 0.682 & 0.697 & 0.187 \\
cluster 3 & 0.123 & 0.362 & 0.000 & 0.1408 & 0.109 & 0.000 \\
cluster 4 & 0.141 & 0.682 & 0.140 & 0.431 & 0.474 & 0.000 \\
cluster 5 & 0.115 & 0.697 & 0.109 & 0.474 & 0.930 & 0.639 \\
cluster 6 & 0.000 & 0.187 & 0.000 & 0.000 & 0.639 & 0.500 \\
\hline
\end{tabular}

Table 19.1: Terms_kl1 of the matrix _ estimated using the variational EM algorithm to $K=6$ clusters 